\title{
LA DEUOTIO DE DECIO MUS
}

\section{Decius Mus' Demotio}

\author{
José Manuel Aldea Celada \\ P.I.F. Junta de Castilla y León \\ Departamento de Prehistoria, Historia Antigua y Arqueología \\ Universidad de Salamanca \\ Correo electrónico: jmaldea@usal.es
}

Fecha de recepción: 22-II-2011

Fecha de aceptación: 2-V-2011

RESUMEN: En la presente comunicación pretendemos abordar el tema de la pervivencia de la Historia Antigua como fuente iconográfica para el arte europeo de la Edad Moderna (el siglo XVII en nuestro caso). En una primera parte, analizaremos el ritual de la denotio, contextualizándolo dentro de la religión romana republicana. A partir de las fuentes literarias prestaremos especial atención al estudio de la denotio de Decio Mus. El siguiente paso será poner lo anterior en relación con Rubens y su ciclo dedicado a la denotio de Decio Mus, intentando explicar qué motivo la elección del tema (comitente y destino de la obra), cuál de las fuentes fue la que inspiró a Rubens y qué elementos iconográficos fueron empleados para dar forma al ritual en las diferente escenas que componen el ciclo.

Palabras clave: Religión romana; denotio; Decio Mus; Peter Paul Rubens; iconografía; método iconográfico.

ABSTRACT: The object we have decided to discuss here is the use of Ancient History as an iconographical source in the European art of the 17th century. We have divided the study in two parts, the first one consists on the analysis of the deuotio ritual contextualizing it within the republican Roman religion. Basing on the literary sources, we shall focus on the Decius Mus deuotio. In the second part, we will connect that ritual with Rubens and his paints dedicated to the Decius Mus deuotio. The next step is try to explain why this story was chosen, in which sources did Rubens get inspired and which iconographical elements were used to shape the ritual in the different scenes in the cycle.

Keywords: Roman religion; denotio; Decius Mus; Peter Paul Rubens; iconography; iconographic method. 


\section{INTRODUCCIÓN}

Los objetivos de esta comunicación son fundamentalmente dos. El primero de ellos es hacer un examen del ritual de la denotio. Para una correcta comprensión del mismo será necesario que lo pongamos en relación con otros rituales de religión romana republicana en general y, más específicamente, con algunos ejemplos que presentan semejanzas, especialmente el sacrificio personal.

El segundo de los objetivos nos llevará a tratar la importancia de la Antigüedad como fuente iconográfica del arte europeo de la Edad Moderna. La generalidad y amplitud de este tema nos obliga a centrarnos en el caso concreto del ciclo elaborado por el pintor Peter Paul Rubens retomando el tema de la denotio de Decio Mus. De esta forma, nos proponemos explicar las causas que motivaron la elección de este tema, que, como tendremos la oportunidad de ver, no responde a un ritual que gozara de especial relevancia dentro de la Historia de Roma ni en las fuentes literarias que nos la relatan.

La consecución de ambos objetivos implica el esfuerzo de combinar dos metodologías de investigación diferentes. El objeto de análisis no es el mismo en los dos casos: en el primero el objeto es el ritual; en el segundo, la obra de arte. La diferencia entre ellos obliga a que las herramientas con las que los examinemos sean diversas: el estudio de la religión romana ha de hacerse partiendo del conocimiento que de ella obtenemos mediante las fuentes (ya sean literarias, arqueológicas, etc.), moviéndonos, por tanto, en el ámbito de la Historia Antigua. La denotio es un ritual que conocemos exclusivamente gracias a que fue recogido por diferentes autores clásicos, perteneciendo a Tito Livio el relato de mayor importancia. No obstante, no nos limitaremos al estudio de los fragmentos literarios, sino que, para que el estudio tenga sentido, será necesario que intentemos explicar sus características mediante la comparación con otros rituales de la religión romana, además de situarlo en su contexto histórico. Solo de esta manera podremos conocer tanto la importancia del ritual como la valoración que del mismo se ha podido extraer en épocas posteriores.

La aproximación a la obra de arte es diferente. Para una correcta adecuación con los objetivos que nos hemos planteado, la metodología que hemos considerado más acertada es la iconográfica. Lo óptimo para la consecución de los objetivos que nos planteamos sería que pudiéramos completar todos los pasos que se marcan ese método, pero la falta de información específica sobre el ciclo elaborado por Rubens no nos permite obtener conclusiones sobre su función cultural concreta, es decir, profundizar en el análisis iconológico'. Sin embargo, es de especial interés el hecho de

1 Nuestra exposición sobre el método iconográfico se basa, en parte, en la reciente publicación de García Mahíques. En su obra podemos encontrar aspectos tanto de historia del método como las herramientas para su manejo y comprensión. En relación con la 
que el ciclo de Rubens se nos haya conservado en dos soportes diferentes: por una parte tenemos los cartones elaborados por el propio Rubens y, por otra, los tapices que resultaron de los mismos.

Dentro de las líneas metodológicas, nuestro interés se centrará en el examen detallado del tema iconográfico. Para la obtención de conclusiones relevantes será necesario que analicemos los diversos aspectos que conforman la obra, desde los motivos menos representativos hasta la composición en general. De este modo construiremos una sólida base para conocer, de forma muy precisa, la adecuación de la obra de Rubens al relato de Tito Livio.

\section{El RitUAL DE LA DEUOTIO}

El primer paso es definir denotio y especificar sus características. De entrada hemos de asumir que no es una tarea sencilla. En líneas generales, podríamos definir deuotio como ritual de la religión romana llevado a cabo en un momento extrema necesidad ante un peligro inminente y consistente en el ofrecimiento de las tropas enemigas y un general romano a los dioses del inframundo.

Esta definición recoge diferentes aspectos que deben ser comentados y aclarados. En primer lugar, se trata de la definición de la denotio en la que un general ofrece su vida a los dioses infernales además de la del ejército enemigo. Sin embargo, el ritual de la denotio no respondió siempre a estas características. Una variante especialmente conocida es la denotio de Cartago, realizada en el 146 a. C. tras la derrota de la ciudad al final de la tercera guerra púnica.

Así pues, debemos explicar qué diferencias hay entre los dos tipos de denotio. Para establecer las diferencias nos basaremos en el artículo de Versnel$^{2}$, desde nuestro punto de vista el más completo a este respecto. Versnel diferencia dos tipos de denotio que denomina denotio hostis, que se correspondería con la deuotio de Cartago, y denotio ducis, la de Decio Mus.

La denotio hostis podría ser entendida como un voto en el cual el general romano, en el caso de Cartago Escipión, ofrece a los dioses el enemigo a cambio de la victoria. En este caso, el cumplimento del voto viene condicionado por la colaboración divina: si los dioses no favorecen la victoria, el general no les ofrecerá el voto prometido. A continuación reproducimos el fragmento de Macrobio en el que se recoge el carmen denotionis asociadado a este tipo de denotio:

definición de Iconografía e Iconología, ver: GARCÍA MAHÍQUES, Rafael, Iconografía e Iconología, vol. 2. Madrid, Ediciones Encuentro, 2009, pp. 13-16.

2 VERSNEL, H. S., “Two types of Roman devotio”. Mnemosyne, 29, 1976, pp. 365-410. 
"Vrbes nero exercitusque sic denouentur iam numinibus enocatis, sec dictatores imperatoresque soli possunt deuouere his uerbis: Dis Pater, Veiouis, Manes, siue nos quo alio nomine fas est nominare, ut omnes illam urbem Carthaginem exercitumque quem ego me sentio dicere, fuga formidine terrore compleatis quique aduersum legiones exercitumque nostrum arma telaque ferent, uti uos eum exercitum eos hostes eosque homines urbes agrosque eorum et qui in his locis regionibusque agris urbibusque habitant, abducatis, lumine supero prinetis exercitumque hostium urbes agrosque eorum quos me sentio dicere uti nos eas urbes agrosque captia aetatesque eorum denotas consecratasque babeatis ollis legibus quibus quandoque sunt maxime hostes deuoti. Eosque ego nicarios pro me fide magistratuque meo pro populo Romano exercitibus legionibusque nostris do denoueo, ut me mmeamque fidem imperiumque legiones exercitumque nostrum qui in his rebus gerundis sunt bene saluos siritis esse. Si haec ita faxitis ut ego sciam, sentiam intellegamque, tunc quisquis hoc notum faxit, ubiubi faxit, recte factum esto onibus atris tribus. Tellus mater, teque Iuppiter obtestor"3.

Presentamos el fragmento en su totalidad para poder hacer comentarios en varias de sus líneas y para poder establecer posteriormente una comparación con la fórmula de la deuotio recogida por Livio para el caso de Decio Mus. Ambos autores pueden haber accedido a las fórmulas gracias a que habrían sido puestas por escrito por si fuera necesario emplearlas en otras ocasiones, de tal forma que se atendiera a la importancia de la reproducción meticulosa de las mismas, una de las características de la práctica ritual romana.

En la primera línea Macrobio nos señala que la deuotio es un ritual que solo lo pueden llevar a cabo dictatores imperatoresque, es decir, los magistrados de la República dotados con imperium. Esta es una característica común en ambos casos, tanto Decio Mus como Escipión contaban con este poder. Avanzando en el texto, ya dentro de lo que sería la fórmula de la denotio, se menciona a los dioses a los que va dirigido el voto: Dis Pater, Veiovis, Manes, los tres son considerados dioses infernales o ctónicos ${ }^{4}$. Tellus y Júpiter aparecen mencionados al final del fragmento y su función es la de testigos.

Lo que el ritual pretende conseguir es simple y viene especificado claramente en el texto: la derrota del enemigo y la salvación del pueblo romano. Sin embargo, lo más interesante es el hecho de que, como ya señalábamos, el voto solo será cumplimentado si se recibe la ayuda de los dioses. Será entonces cuando estos reciban tres ovejas negras en sacrificio.

Por tanto, vemos que el ritual no exige en ningún momento el sacrificio de un general romano para la salvaguarda de Roma y que contiene

3 Macrob., Sat., 3. 9.9 y ss.

4 Dis Pater aparece asociado a Perséfone en varios rituales, como los ludi saeculares celebrados en el 249 (ver Val. Max., 2. 4. 5); sobre Veiovis es poca la información que tenemos, sería una divinidad ctónica asociada a fuerzas naturales como el rayo. 
todos los elementos necesarios para poder ser considerado un voto ${ }^{5}$. A pesar de ello, no todos los autores lo consideran un voto. Rawson, por ejemplo, considera que se trataría de una consecratio al entender que el único elemento del voto sería el sacrificio de las tres ovejas negras ${ }^{6}$. No nos detenemos en esta polémica, pues queda al margen de lo que pretendemos estudiar en esta comunicación.

Con la información obtenida a partir del texto de Macrobio podemos concluir que la deuotio hostis (tal y como la llama Versnel) es un ritual por el cual se pide a los dioses que favorezcan la victoria romana a cambio de una ofrenda. Al fin y al cabo, es un ritual que se reduce al tópico do ut des.

Antes de pasar al examen de la denotio de Deciu Mus, cabe preguntarnos si este ritual fue empleado en otras ocasiones o solo en Cartago. Según Macrobio, esta forma de la deuotio se empleó en varias ocasiones, como Veyes y Corinto. A pesar de ello, ninguna otra fuente hace alguna mención a este respecto. En el caso de Veyes, cuya toma y destrucción es bien conocida a través de diversas fuentes, llama la atención que se realizara una enocatio, ritual al que también recurrirá Escipión en la toma de Cartago. Esta coincidencia puede llevarnos a pensar que la enocatio y la denotio pudieran ser rituales asociados, pero no tenemos ninguna evidencia que permita asegurarlo, debiendo quedar como una mera conjetura.

Pasamos ahora al análisis de la denotio de Decio Mus. Al igual que hicimos en el caso anterior, reproduciremos el fragmento de Tito Livio en el que se recoge la fórmula del ritual:

"Romani consules, priusquam educerent in aciem immolauerunt. Decio caput iocineris a familiari parte caesum haruspex dicitur ostendisse: alioqui acceptam dis hostiam esse; Manlium egregie litasse. «Atqui bene habet» inquit Decius, «si ab collega litatum est). Instructis, sicut ante dictum est, ordinibus processere in aciem. Manlus dextro, Decius laeno cornu praeerat. Primo utrimque aequis uiribus, eodem ardore animorum gerebatur res; deinde ab laeuo cornu hastati Romani, non ferentes impressionem Latinorum, se adprincipes recepre. In hac trepidatione Decius consul M. Valerium magna noce inclamat: «Deorum» inquit «ope, M. Valeri, opus est; agedum, pontifex publicus populi Romani, praei nerba quibus me pro legionibus denoueam». Pontifex eum togam praetextam sumere iussit et uelato capite, manu subter togam ad mentum exserta, super telum subiectum pedibus stantem sic dicere: «Iane Iuppiter Mars pater Quirine Bellona Lares Diui Nouensiles Di Indigetes Diui quorum est potestas nostrorum hostiumque Dique Manes, uos precor ueneror ueniam peto oroque uti populo Romano Quiritium vim nictoriam prosperetis, hostesque populi Romani Quiritium terrore formidine morteque adficiatis. Sicut uerbis nuncupani, ita pro re publica

5 VERSNEL, H. S., op. cit., 1976, pp. 176 y ss.

6 RAWSON, Elizabeth, “Scipio, Laelius, Furius, and the ancestral religion” en RAWSON, Elizabeth, Roman Culture and Society. Collected Papers. Oxford, Clarendon Press, 1991, pp. 98. 
populi Romani Quiritium, exercitu legionibus auxiliis populi Romani Quiritium, legiones auxiliaque hostium mecum Deis Manibus Tellurique denoueo»"7.

La historia de Decio Mus nos la presenta Livio dentro del contexto de la guerra latina, es un momento en el que Roma está consolidando su hegemonía frente al resto de pueblos del Lacio. Es en el transcurso de esta guerra donde Decio se verá obligado a recurrir al ritual de la denotio para evitar la derrota de Roma en la batalla de Verésis. Decio ocupaba el consulado en este año, el 340 a. C., junto con Tito Manlio.

Son bastantes los puntos que cambian en comparación con la fórmula anterior. Lo más importante, sin duda, es el hecho de que el propio Decio entregue su vida como parte fundamental del ritual. No obstante, y aunque pueda resultar extraño, no es algo atípico o extraño dentro de la religión romana. Muestra de ello es el prodigio relacionado con el lacus Curtius, que recibe su nombre por la grieta que se abrió en el foro romano y que no pudo ser cerrado hasta que no fue entregado lo más valioso para Roma, a saber, el joven soldado Marcus Curtius en representación del valor y de la juventud. Este joven soldado, montado en su caballo, se lanzó dentro y terminó así con el prodigio funesto ${ }^{8}$.

Más allá de la propia fórmula, llama especialmente nuestra atención la forma como, según Livio, tuvo Decio conocimiento de que su sacrificio iba a ser necesario. Fue mediante un sueño, compartido con su colega de consulado, como se les da a conocer que el general de un bando y las legiones del otro deberían ser sacrificadas?. Los cónsules decidirán hacer un sacrificio para obtener el favor de los dioses. En el sacrificio será donde se intuya que Decio habrá de ser el que se sacrifique al aparecer la protuberancia del hígado de su víctima mutilada, aspecto siempre negativo según los exta harupicinalis ${ }^{10}$.

En el transcurso de la batalla es cuando se produce la propia denotio. Decio teme que su ejército pueda ser derrotado y pide al pontífice Marco Valerio que le dicte la fórmula para cumplir con lo que se les había anunciado en el sueño, su propio sacrificio. La fórmula recogida por Livio presenta muchos aspectos que debemos comentar:

Los dioses a los que ahora se honra son muy variados. Se recurre a Jano para abrir la invocación, a Bellona por el contexto bélico, a los Lares como patrones del terreno donde se desarrollan las acciones humanas,

7 Liv., 8. 9. 1-8.

8 Esta historia debió de ser bien conocida, pues se conserva en bastantes fuentes: Liv., 7. 6. 1-7; Val. Max., 5. 6. 2; Dio., 30.1 en Zon., 7. 25 y Dion. Hal., 14. 11, entre otros.

9 Liv., 8. 6. 9-11.

10 Sobre los exta, ver RASMUSSEN, Susanne William, Public Portents in Republican Rome. Roma, L'Erma di Bretschneider, 2003. 
Manes y Tellus como receptores de la ofrenda, Novensiles e Indigentes como referencia a la totalidad de los dioses romanos. La mención de Júpiter, Marte y Quirino es una muestra del carácter arcaico del ritual, una evidencia de la antigua triada romana. Según Dumézil, su presencia en la fórmula se justifica por su poder sobre las tres partes constitutivas de la vida en sociedad (la soberanía, la fuerza física/el valor y la fecundidad/la prosperidad) ${ }^{11}$. A pesar del mayor número de dioses enumerados, los que finalmente son receptores de la ofrenda son los mismos que en la deuotio de Cartago, los Manes y Tellus.

El que solicita la ayuda de los dioses vuelve a ser un general romano, Decio en esta ocasión. Y la ayuda solicitada es la misma, la salvación del pueblo romano y la victoria en la batalla. La novedad que se introduce en esta ocasión es que lo que se ofrece ya no son unas ovejas negras, sino el propio general romano y los ejércitos enemigos. El cumplimiento del voto conllevaría la muerte de Decio y la derrota de los enemigos de Roma.

Otro aspecto de interés el hecho de que Decio debió convertirse en sacer para poder ser aceptado como ofrenda. El término sacer hace referencia a aquello que pertenece a los dioses. Así pues, Decio, una vez que fue "consagrado", debía morir, ya no pertenecía al mundo de los humanos. Decio, en cumplimiento de sus obligaciones, se abalanzó montado en su caballo (recuérdese, al igual que en el prodigio de lacus Curtius) contra el enemigo para encontrar la muerte. No obstante, las fuentes contemplan la posibilidad de que alguien declarado sacer no encontrara la muerte, pues se nos explica qué se debe hacer para completar el voto: una estatua debe ser enterrada ${ }^{12}$.

Así pues, la denotio ducis (una vez más, según la terminología de Versnel) presenta una consecratio como parte esencial de la misma. A diferencia de la primera que comentábamos, ahora la ayuda de los dioses llega únicamente después de que el general ha ofrecido su vida y ésta le ha sido arrebatada por los enemigos. Lo más importante aquí es que los dioses reciban la vida del general o, en caso de que esta no se produjera, mediante la sustitución de la misma por el enterramiento de la estatua que hemos mencionado.

La denotio de Decio es la primera de la que tenemos constancia, pero no parece haber sido única. Cicerón habla de otras dos ocasiones en las que se empleó este tipo de denotio. Es destacable que quienes recurrieran a este ritual fueran los sucesores del propio Decio: su hijo durante la lucha contra los etruscos y su nieto contra Pirro $^{13}$. Mas fue un ritual que no tuvo mucho éxito, o, al menos, las fuentes no prestan especial atención al comentario de

11 DUMÉZIL, Georges, La religione romana arcaica. Mitti, leggende, realtà. Milán, BUR Saggi, 2007, p. 157.

12 Liv., 8. 10. 12. BEARD, Mary, John NORTH y Simon PRICE, Religions of Rome. Vol.

1. Cambridge, Cambridge University Press, 1998, p. 32.

13 Cic., Disp. Tusc., 1. 89 y Liv., 8. 10. 12-14. 
los diferentes casos, pudiendo haberse producido en más ocasiones y no haber sido recogido por ellas.

\section{Rubens y la Deutio de Decio Mus:}

Comenzamos ahora la parte dedicada al estudio del ciclo que Rubens dedicó a la historia de la denotio de Decio Mus. En primer lugar, queremos volver a incidir en algunos aspectos sobre la metodología empleada.

En la introducción hemos señalado que los pasos marcados por el método iconográfico no pueden ser cumplimentados en su totalidad. Siguiendo a Panofsky, son tres los niveles de análisis que plantea este método ${ }^{14}$. El primero es la significación primaria o natural, subdividida en significación fáctica y significación expresiva. Este primer nivel busca la identificación de los motivos que componen una determinada obra. Panofsky considera su enumeración como una descripción pre-iconográfica.

El segundo nivel es el de la significación secundaria o convencional. Este nivel se corresponde con el análisis iconográfico. Es ahora donde los motivos y figuras descritas en el nivel anterior se identifican con lo que pretenden representar. En este nivel es donde se establece el tema iconográfico de la obra. Las alegorías y las historias que se pretenden representar se dan a conocer en este nivel. En nuestro análisis del ciclo de Decio Mus, éste será el nivel de mayor importancia.

Por último tenemos el tercer nivel, la significación intrínseca o contenido. Lo que este nivel pretende conocer es la significación de la obra en relación con la sociedad que la ha generado. Nuestro análisis de este nivel es el que se verá truncado por la falta de información en torno a la obra elaborada por Rubens más allá de sus aspectos meramente iconográficos o estilísticos. A pesar de ello, intentaremos profundizar lo más que nos sea posible en el análisis iconológico, que es con el que se corresponde este nivel.

Estos tres niveles serán la base para el examen del ciclo de Decio Mus, pero comenzaremos explicando algunas consideraciones previas. En primer lugar, es necesario indicar que Rubens realizó este ciclo hacia 1616. El ciclo tendría su origen en el contrato firmado entre el comerciante genovés Franco Cattaneo, el tapicero Jan II Raes y el historiador Frans Sweerts el Joven. Rubens recibiría el encargo de una serie de cartones a partir de los cuales elaborar los tapices.

El ciclo completo estaría formado por nueve escenas, de las cuales, siete conformarían la historia de Decio y dos funcionarían como apertura y cierre del ciclo, ambas con motivos mitológicos y alegóricos. Actualmente

14 PANOFSKY, Erwin, El significado en las artes visuales. Madrid, Alianza, 1998 (imp. 2000), pp. 47 y ss. En estas páginas encontramos la descripción detallada de los niveles de análisis y la explicación de los términos iconografía e iconología. 
se conservan seis cartones en el Liechtenstein Museum de Viena ${ }^{15}$, los bocetos preliminares y los tapices elaborados a partir de ellos, que fueron incorporados a la Colección Real por Felipe $\mathrm{IV}^{16}$. Gracias a que se conserven en la Colección Real conocemos como sería la última de las escenas (fig. 7), ya que no se conservan ni el boceto ni el cartón de Rubens.

Entrando en el examen de las obras elaboradas por Rubens, a modo de idea general cabe destacar el gusto del pintor por la representación de motivos de tipo arqueológico o, más bien, propios del gusto por las antigüedades en las obras del Renacimiento italiano, que habrían influenciado fuertemente a Rubens durante su estancia en dicho país. En todas las imágenes recogidas en el anexo se pueden apreciar infinitud de detalles que nos acercan a elementos emblemáticos de la cultura romana antigua, presentándose de forma reiterada en su gran mayoría. Como ejemplos podemos señalar los estandartes de las legiones y las siglas SPQR, las fasces, y, destacando especialmente, las armaduras. Rubens hace mucho hincapié en todos estos motivos, que se engarzan para conformar y ser el sustento del tema iconográfico.

La fig. 1, Alocución a los oficiales, es buena muestra de lo que indicábamos anteriormente. En ella podemos apreciar la profusión de los motivos señalados (estandartes y armaduras). Esta primera figura presenta a Decio Mus sobre un pedestal dirigiéndose a unos oficiales de su ejército. Rubens ha querido representar aquí el momento en el que Decio se habría dirigido a las tropas para informar del sueño que presagiaba su destino.

Es en las figuras 2 y 3 donde encontramos un mayor número de motivos que presentan un especial interés. La fig. 2, Decio consulta el oráculo, es un momento crucial dentro de la historia narrada por Livio. Aquí Rubens recurre de nuevo a motivos que nos ayudan a comprender el tema iconográfico de la obra. Volvemos a encontrar a Decio con su armadura de general romano y la toga púrpura de su rango consular. Tras él se encuentran los lictores, y uno de ellos apoya en el suelo las fasces, otra muestra del rango consular de Decio. En relación con la religión romana, cabe destacar la minuciosidad con la que Rubens recrea el sacrificio y la lectura de las extrañas de la víctima. Los victimarios se presentan siguiendo las características de los relieves altoimperiales ${ }^{17}$. No podemos dejar de mencionar que Rubens se desvía del relato de Livio al incluir en la escena dos sacerdotes. Por una

15 El Liechtenstein Museum, en su página web, muestra las imágenes del ciclo que se encuentran en su colección, ver: http://www.liechtensteinmuseum.at/en/pages/1420.asp.

16 Sobre los tapices, la mejor obra dedicada a su análisis es HERRERO CARRETERO, Concha, Rubens 1577-1640. Colección de tapices. Madrid, Patrimonio Nacional, 2008, pp. 27-43.

17 Ver: BEARD, Mary, John NORTH y Simon PRICE, Religions of Rome. Vol. 2. Cambridge, Cambridge University Press, 1998, pp. 146 y ss. En estas páginas se encuentran algunos ejemplos de esos relieves altoimperiales a los que hacemos referencia. 
parte tendríamos al haruspex, quien habría oficiado el sacrificio y examinado las entrañas de las víctimas. El baruspex, cuyo nombre no aparece en las fuentes, sería el que mostró a Decio la cabeza del hígado mutilada, símbolo del mal presagio. Este sacerdote, como conductor del sacrificio, lleva la cabeza cubierta con la toga. A su lado, Rubens prefiere introducir la figura de otro sacerdote para ponerlo en relación con los acontecimientos que seguidamente relata Livio. Se trata del pontífice Marco Valerio, vistiendo la toga dorada. Livio no menciona la intervención del pontífice en la consulta de los exta, es una libre interpretación de Rubens, que pretendería otorgar una mayor importancia a Marco Valerio.

La figura 3 es clave para entender la importancia que Rubens concedió al pontífice. Livio nos dice que durante la batalla, ante la pérdida de fuerza de la parte del ejército comandada por Decio, el cónsul pediría al pontífice que le dictara la fórmula para llevar a cabo la denotio ${ }^{18}$. Lo que Rubens representa es, atendiendo a los motivos que conforman el cartón, un ritual de consecratio. Decio y Marco Valerio son las dos figuras principales, ambas con la cabeza cubierta como corresponde a aquellos que participan en un ritual. Decio mantiene sus atributos consulares, la toga púrpura y los lictores portando las fasces. En ninguna de las fuentes aparece descrito este momento tal como lo ha representado Rubens, es una libre interpretación del pintor. Es interesante que haya optado por aislar el momento de la consecratio, pues de este modo está concediendo especial importancia al aspecto diferenciador entre la denotio hostis y la denotio ducis. No obstante, Rubens es fiel a algunos detalles del texto de Livio. La representación de Decio sigue con gran exactitud las indicaciones que en el texto da Marco Valerio: Decio se encuentra de pie sobre una lanza, se cubre la cabeza y se toca el mentón con la mano.

Con el examen de estas dos figuras hemos pretendido especificar el papel que cada figura ocupa en relación con el relato de Livio y las formas rituales romanas, de forma que no se produzcan errores de interpretación como el que presenta Herrero Carratero, quien no hace una diferencia entre angures, pontifices y haruspices ${ }^{19}$. No debemos caer en el error de confundir los métodos de adivinación de augures y haruspices, pues cada uno tenía unas funciones muy bien delimitadas dentro del sistema adivinatorio romano. Por tanto, lo que encontramos en las escenas de Rubens son: análisis de los exta por parte de un baruspex y una consecratio oficiada por un pontifex.

$\mathrm{Al}$ igual que la fig. 3, la 4 tampoco aparece recogida por las fuentes. Aquí Rubens nos presenta el momento previo a la batalla en el que Decio, de nuevo portando su atuendo de general consular, despide a los lictores, que se alejan llevando las fasces con ellos.

18 Liv., 8. 9. 4.

19 HERRERO CARRETERO, Concha, op. cit., p. 33. 
La fig. 5, Batalla de Véseris y muerte de Decio, vuelve a ofrecernos un buen número de aspectos que merecen un comentario. La imagen que hemos seleccionado para nuestro anexo es el modelo que se encuentra en el Museo Nacional del Prado y no el cartón del Liechtenstein Museum. Esta escena de la historia de Decio ha llamado la atención de los estudiosos de la obra de Rubens, y no sin razón, por su valor estilístico, poniéndolo en relación con la Batalla de Angbiari de Leonardo da Vinci ${ }^{20}$ (no se conserva, se encontraba en el Palazzo Vecchio de Florencia). Por nuestra parte, continuaremos, al igual que hemos hecho con las figuras anteriores, con el estudio de los motivos que permiten establecer vínculos entre Rubens y el ritual narrado por Livio.

Herrero Carretero (ver las páginas de la referencia 20) acierta al señalar que Rubens introduce un cambio al presentar a Decio herido de muerte por una lanza y no por una nube de flechas ${ }^{21}$. Este cambio lo introduciría el pintor por su capacidad para ser adaptado al esquema compositivo que le ofrecía la mencionada Batalla de Anghiari de Leonardo, sin deberse a razones de otro tipo. El resto de motivos que componen este modelo no presentan ninguna novedad, se repiten las armaduras y estandartes, conformando en conjunto un torbellino de movimiento y tensión que reproducen el fragor de la batalla en el momento álgido: Decio ha perdido su vida y, gracias a su sacrificio, el ejército romano, liderado ahora por el cónsul Tito Manlio, se impone al latino, que comienza la huida.

La elección del modelo y no del cartón se justifica por la presencia en el primero de una figura que no aparecerá en el segundo. Se trata de una figura alada que se aparece sobre el grupo central. Esta figura porta atributos iconográficos que permiten identificarla con una alegoría de la Victoria, de hecho, es muy similar a la que encontramos en la fig. 9. Para su representación, Rubens acude al modelo clásico de la victoria alada portadora de una corona de laurel. En su análisis de este modelo, Herrero Carretero considera esta figura como "un genio angelical que desciende de la altura y presenta una rama de laurel como símbolo de la victoria del cónsul agonizante" 22 . Por nuestra parte, no consideramos que se trate de un genio angelical, sino de la propia alegoría de la Victoria. Del mismo modo, observando la imagen con detalle, se puede apreciar que porta una corona de laurel, siguiendo los preceptos clásicos, y una palma. Este motivo es el que nos permite establecer una conexión con la doctrina cristiana. La palma es el motivo que acompaña en numerosas representaciones a los mártires

20 La importancia concedida a este hecho puede apreciarse, por ejemplo, en AYALA MALLORY, Nina, La pintura flamenca del siglo XVII. Madrid, Alianza, 1995, pp. 191-121 y HERRERRO CARRETERO, Concha, op. cit., pp. 36 y ss. En la primera referencia puede verse un análisis más detallado de las correspondencias estilísticas con otras del mismo autor.

21 Liv., 8. 9. 12.

22 HERRERO CARRETERO, Concha, op. cit., p. 39. 
(sirva de ejemplo la magnífica Santa Catalina de Alejandría de Caravaggio). Así pues, Rubens uniría la tradición clásica y la cristiana mediante esta figura. Victoria y martirio conforman el significado último de este modelo.

La significación de este episodio de la historia de Decio es la que puede dotar a la obra en su conjunto de un valor moral: el sacrificio como medio para alcanzar la victoria. En este punto sí que compartimos la interpretación de Herrero Carretero, al considerar el ciclo como una visión neoestoica del héroe ${ }^{23}$.

El resto de figuras que constituyen el ciclo presentan una cantidad de información menor que las precedentes, por lo que nuestro comentario será más breve. La fig. 6, Funerales de Decio Mus, tiene interés especialmente por el despliegue de objetos que Rubens incluye como parte del botín de guerra. El conocimiento casi arqueológico del pintor se pone excepcionalmente de manifiesto en este cartón, pudiendo destacarse el conjunto de objetos situados en último plano.

La fig. 7, Tito Manlio presenta a los senadores romanos un trofeo tras la victoria de Véseris, es el final de la historia de Decio. Rubens concluye el ciclo con una escena que no aparece en Livio.

Tito Manlio presidiría la comitiva que se dirige al senado para informar de la victoria sobre los latinos. Esta escena, como indicábamos más arriba, la conocemos gracias a que se ha conservado el tapiz, pues el cartón se ha perdido.

Las figs. 8 y 9, Marte y Rea Silvia, los padres de Rómulo y Remo y La virtud militar y la victoria, son las escenas que Rubens abría concebido para abrir y cerrar el ciclo. Si las figuras comentadas anteriormente responden a un esquema narrativo, estas dos tienen un fuerte carácter mitológico y alegórico. La fig. 8 puede considerarse un alarde de conocimiento mitológico por parte del pintor, ya que presentar una escena de Marte y Rea Silvia no tiene ninguna conexión ni con la historia de Decio Mus ni con la interpretación que la misma podamos hacer. Si esta escena abría el ciclo, puede entenderse como una referencia al origen mismo de la historia de Roma. Queremos señalar un detalle de este cartón, el altar situado junto a Rea Silvia, que presenta dos esfinges en su basamento. Si observamos la fig. 2, Decio consulta el oráculo, veremos que Rubens emplea en ambos altares la esfinge. La interpretación de su uso es complicada, pues interpretarlas a partir de su significado en el mito de Edipo, es decir, como símbolo de lo enigmático o de lo misterioso, no tiene mucho sentido en relación con la significación general del ciclo.

La última figura, la 9, cerraría el ciclo. Su carácter es completamente alegórico. La imagen la conforman dos figuras alegóricas: la Victoria y la Virtud militar o alegoría de la Guerra. La Victoria sigue el planteamiento de aquella figura que aparecía en el modelo de la Batalla de Véseris y muerte

23 HERRERO CARRETERO, Concha, op. cit., p. 39. 
de Decio. Es una victoria alada clásica que porta la corona de laurel, símbolo inequívoco de la victoria, y la palma, que hemos interpretado como un motivo que aporta el valor cristiano del martirio a la figura clásica. La Virtud militar también sigue los preceptos clásicos, recordando a las principales mujeres guerreras que se conocen en la mitología clásica, como la misma Minerva y las amazonas. Rubens recurre a esos modelos clásicos para adaptarlos a la manera en que se representaban estas alegorías desde el Renacimiento ${ }^{24}$, a saber, una figura femenina que se viste con motivos iconográficos que permiten su identificación. En este caso en particular, los motivos que permiten su identificación son el atuendo militar, la lanza, la espada y el pie en actitud victoriosa sobre el globo terráqueo.

\section{ConClusión:}

Para terminar, simplemente resaltaremos los aspectos fundamentales que hemos sacado a la luz en nuestro análisis. En primer lugar, consideramos que el ritual de la denotio presenta unas características que lo convierten en único dentro del amplio número de rituales que conformaban la religión pública romana. A pesar de ello, presenta puntos coincidentes con algunos de ellos, como la consecratio, presente también, por ejemplo, en el uer sacrum, y el sacrificio personal, aunque menos común (prodigio del lacus Curtius).

El sacrificio personal que exigía la denotio ducis supuso, aunque Livio señale que no es estrictamente necesario y que puede ser suplido por rituales compensatorios $^{25}$, que no fuera frecuente su empleo, quedando como un ritual arcaico que llamó la atención de autores de época tardorrepublicana y altoimperial.

La importancia del sacrificio personal es la clave interpretativa que puede estar detrás de la elección de la historia de Decio ya en siglo XVII. La historia como magistra vitae a través de exempla convierte a Decio en una historia de actualidad en ese siglo. Sin embargo, y aunque se le añada el valor de martirio cristiano, no fue un tema que gozara de éxito en el arte europeo de la Edad Moderna. De hecho, no se repite en obras posteriores a Rubens.

Por último, queremos reivindicar la necesidad de que los estudios rompan las barreras de las áreas establecidas en los ámbitos académicos. Es necesario que la Historia y la Historia del Arte, por centrarnos en las áreas que nos atañen en esta comunicación, sean disciplinas afines. Un historiador tiene que conocer el arte producto de cada contexto social y cultural. Un

24 Durante el Renacimiento y el Barroco tuvieron gran auge las obras dedicadas al estudio de las alegorías y emblemas, que fueron la base para numerosos artistas de la época. Un ejemplo de excepcional valor es la obra Iconología, de Cesare Ripa. Puede consultarse la edición en español: RIPA, Cesare, Iconología. 2 vols. Madrid, Akal, 1987.

25 Liv., 8. 10. 11-14. 
historiador del arte debe conocer ese contexto para poder entender qué motivo la creación de un arte con unas características específicas en cada período histórico y no limitarse a la descripción estilística.

En lo que respecta la Historia Antigua y la Historia del Arte, su conexión es especialmente estrecha. Como hemos pretendido mostrar, la Historia Antigua permite llevar más allá de la simple mención la identificación de un tema iconográfico puntual. No es suficiente señalar que Rubens elaboró un ciclo de dedicado a la denotio de Decio Mus, es necesario saber qué es la denotio y qué significa este ritual. Ante el recurso constante de a temas de la Antigüedad por parte de los artistas de todas las épocas, consideramos obligatorio reivindicar el conocimiento de la Historia Antigua para la correcta interpretación y puesta en valor de una gran variedad de obras.

\section{Bibliografía Y FUENTES LITERARIAS:}

AYALA MALLORY, Nina, La pintura flamenca del siglo XVII. Madrid, Alianza, 1995.

BEARD, Mary, John NORTH y Simon PRICE, Religions of Rome. 2 vols. Cambridge, Cambridge University Press, 1998.

DUMÉZIL, Georges, La religione romana arcaica. Mitti, leggende, realtà. Milán, BUR Saggi, 2007.

GARCÍA MAHÍQUES, Rafael, Iconografía e Iconología. 2 vols. Madrid, Ediciones Encuentro, 2009.

HERRERO CARRETERO, Concha, Rubens 1577-1640. Colección de tapices. Madrid, Patrimonio Nacional, 2008.

PANOFSKY, Erwin, El significado en las artes visuales. Madrid, Alianza, 1998 (imp. 2000).

RASMUSSEN, Susanne William, Public Portents in Republican Rome. Roma, L’Erma di Bretschneider, 2003.

RAWSON, Elizabeth, "Scipio, Laelius, Furius, and the ancestral religion" en RAWSON, Elizabeth, Roman Culture and Society. Collected Papers. Oxford, Clarendon Press, 1991, pp. 80-101.

RIPA, Cesare, Iconología. 2 vols. Madrid, Akal, 1987.

VERSNEL, H. S., "Self-sacrifice, compensations and the anonymous gods" en VERNAT, Jean-Pierre (et. al.), Le sacrifice dans l'Antiquité. Ginebra, Fondation Hardt, 1981, pp. 135-194.

— “Two types of Roman devotio". Mnemosyne, 29, 1976, pp. 365-410.

Fuentes literarias: 
CICERÓN, Marco Tulio, De finibus bonorum et malorum. Español-latin. México, Universidad Nacional Autónoma de México, 2003.

- Disputas tusculanas. Español-latin. México D. F., Universidad Nacional Autónoma de México, 1979.

DIÓN CASIO, Dio's Roman History. Londres-Cambridge, William Heinemann-Harvard University Press, 1990 y ss.

DIONISIO DE HALICARNASO, The Roman Antiquities of Dionysius of Halicarnassus. Londres-Cambridge, William Heinemann-Harvard University Press, 1963 y ss.

LIVIO, Tito, Historia de Roma desde su fundación. Madrid, Gredos, 1990 y ss.

- Livy. Ab urbe condita. Londres-Cambridge, William HeinemannHarvard University Press, 1965 y ss.

MACROBIO, Ambrosio Aurelio Teodosio, Les Saturnales: Livres I-III. París, Les Belles Lettres, 1997.

VALERIO MÁXIMO, Facta et dicta memorabilia. 2 vols. Stuttgart, Teubner, 1998.

5. Índice de ilustraciones:

Fig. 1: Alocución a los oficiales. Fuente: HERRERO CARRETERO, Cocha, op. cit., p. 29.

Fig. 2: Decio consulta el oráculo. Fuente: Idem, p. 33.

Fig. 3: Marco Valerio consagra a Decio. Fuente: Idem, p. 30.

Fig. 4: Decio despide a los lictores. Fuente: Idem, p. 31.

Fig. 5: Batalla de Véseris y muerte de Decio. Idem, p. 37.

Fig. 6: Funerales de Decio Mus. Idem, p. 40.

Fig. 7: Tito Manlio presenta a los senadores romanos un trofeo tras la victoria de Véseris. Idem, p. 88.

Fig. 8: Marte y Rea Silvia, los padres de Rómulo y Remo. Idem, p. 42.

Fig. 9: La virtud militar y la victoria. Idem, p. 41.

Anexo: el ciclo de Decio Mus. 


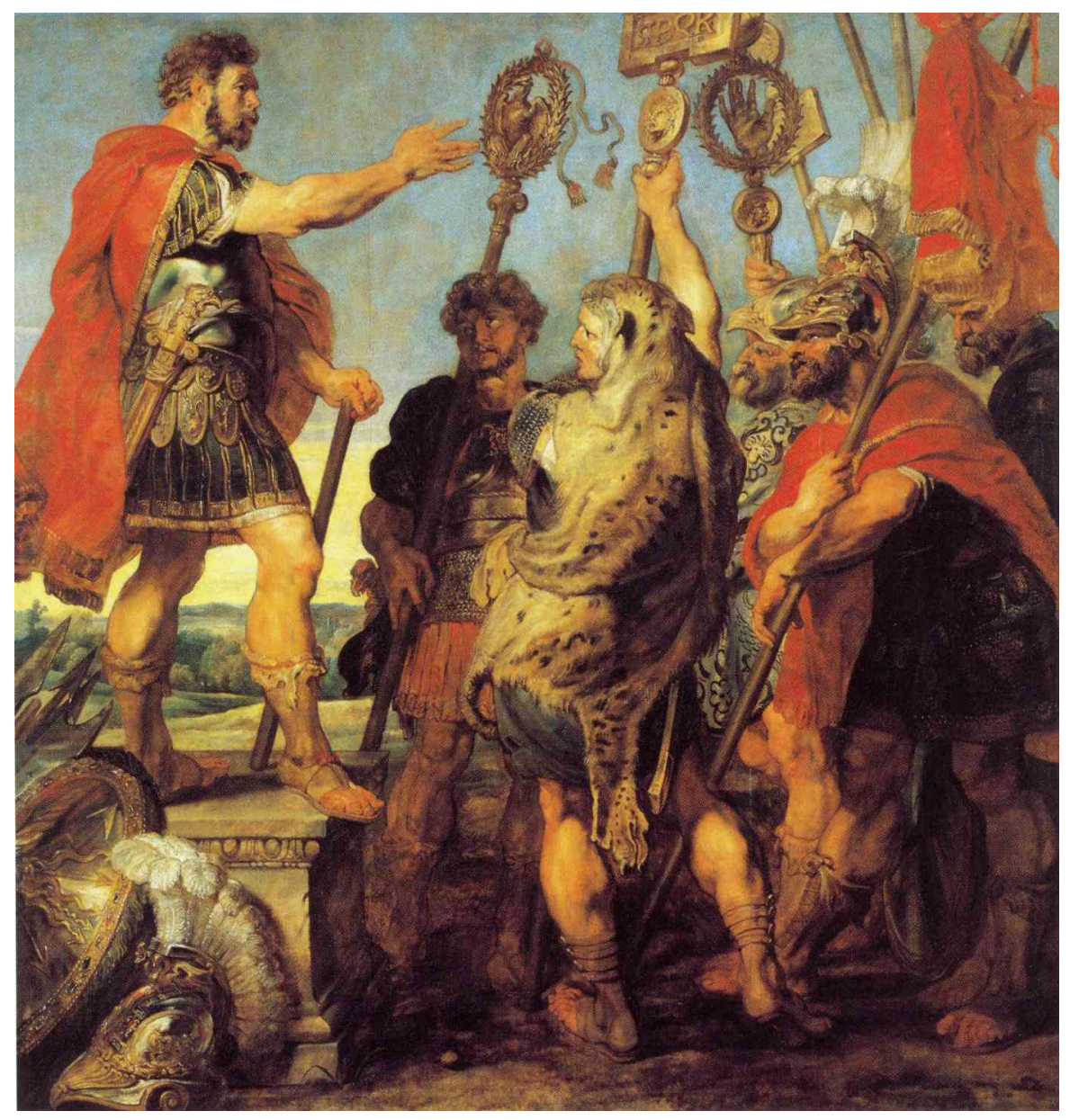

Figura 1. 


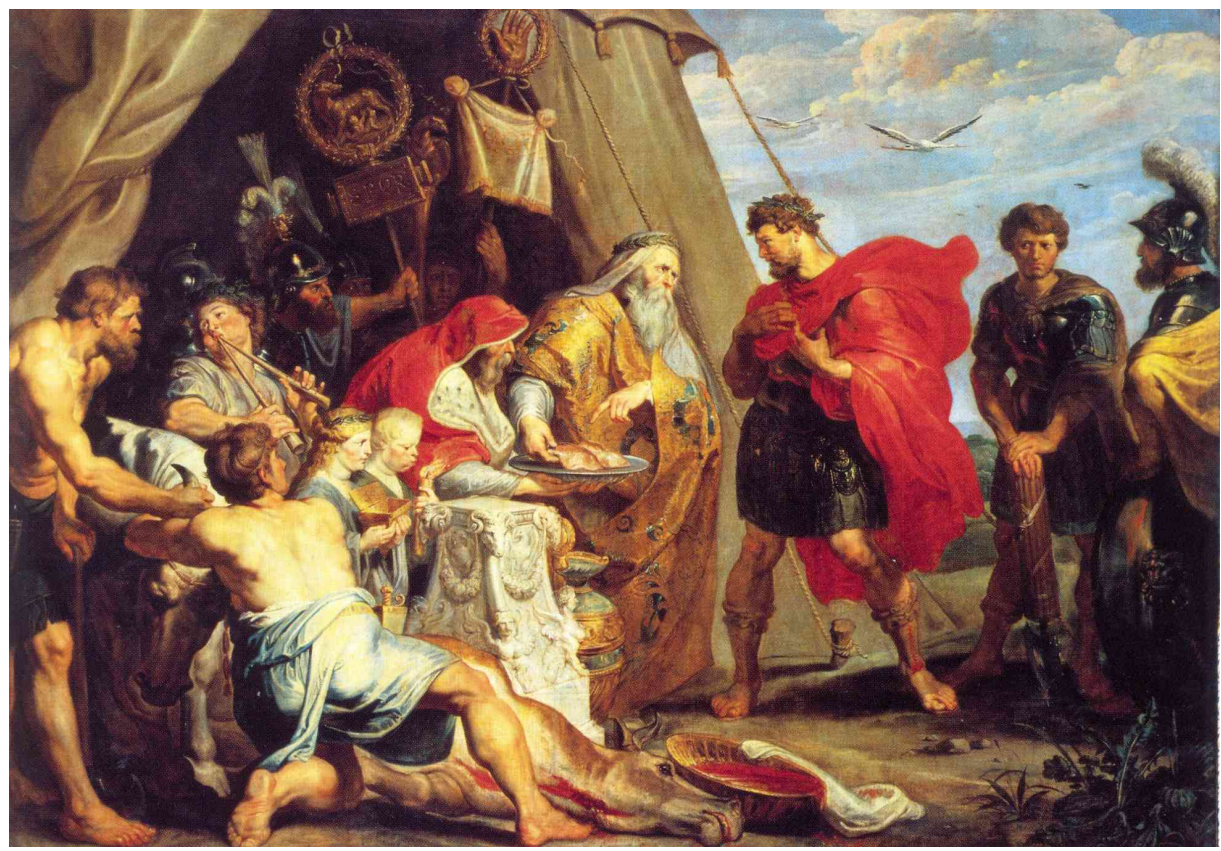

Figura 2.

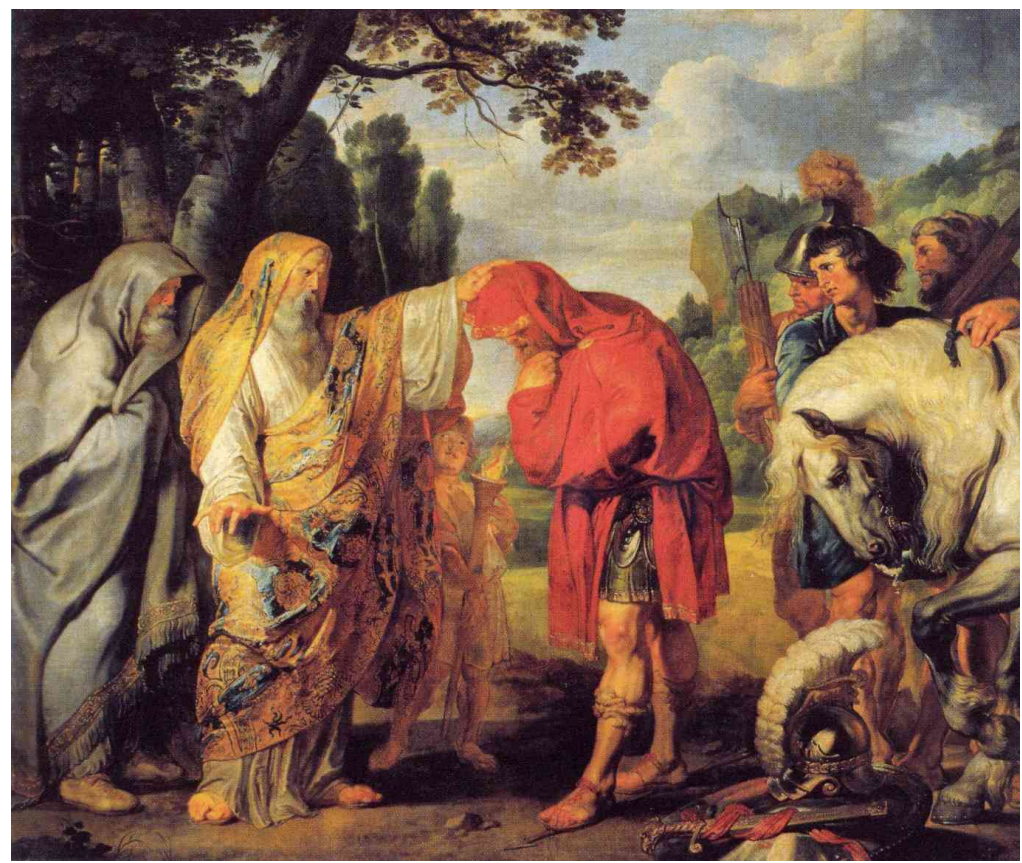

Figura 3. 


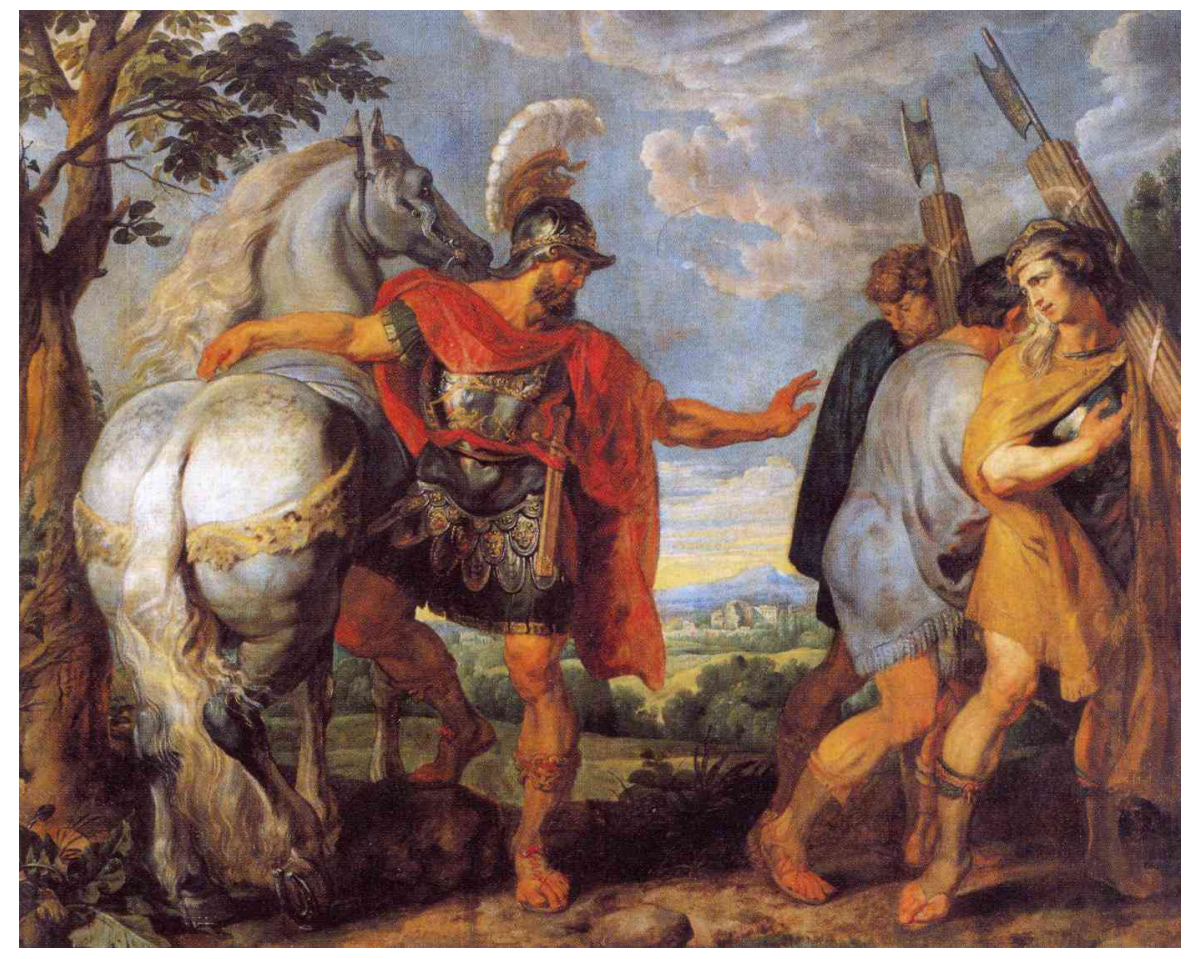

Figura 4.

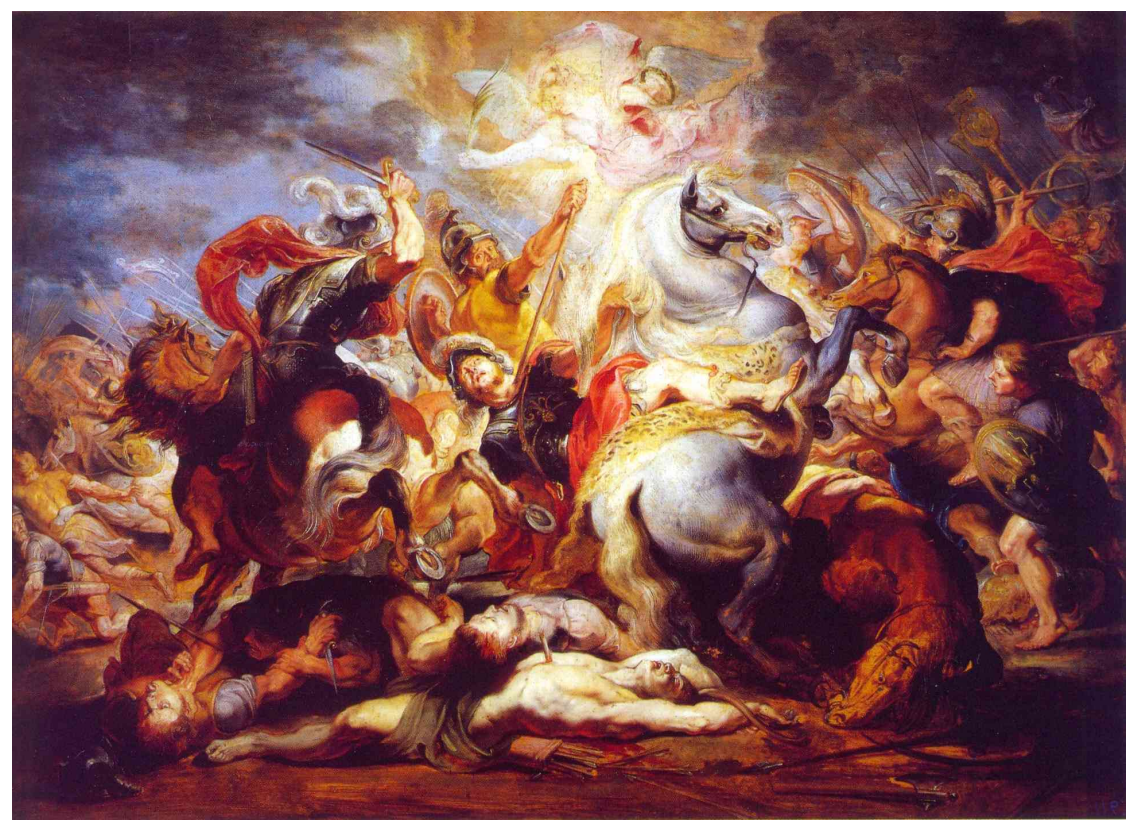

Figura 5. 


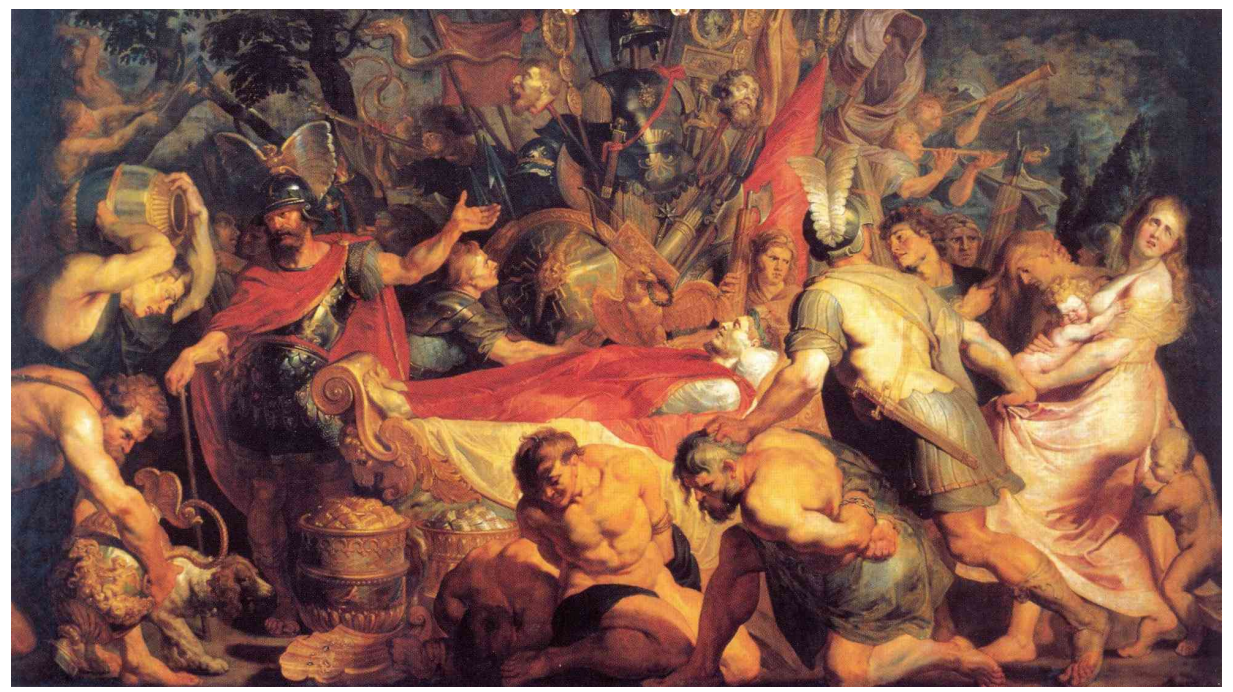

Figura 6.

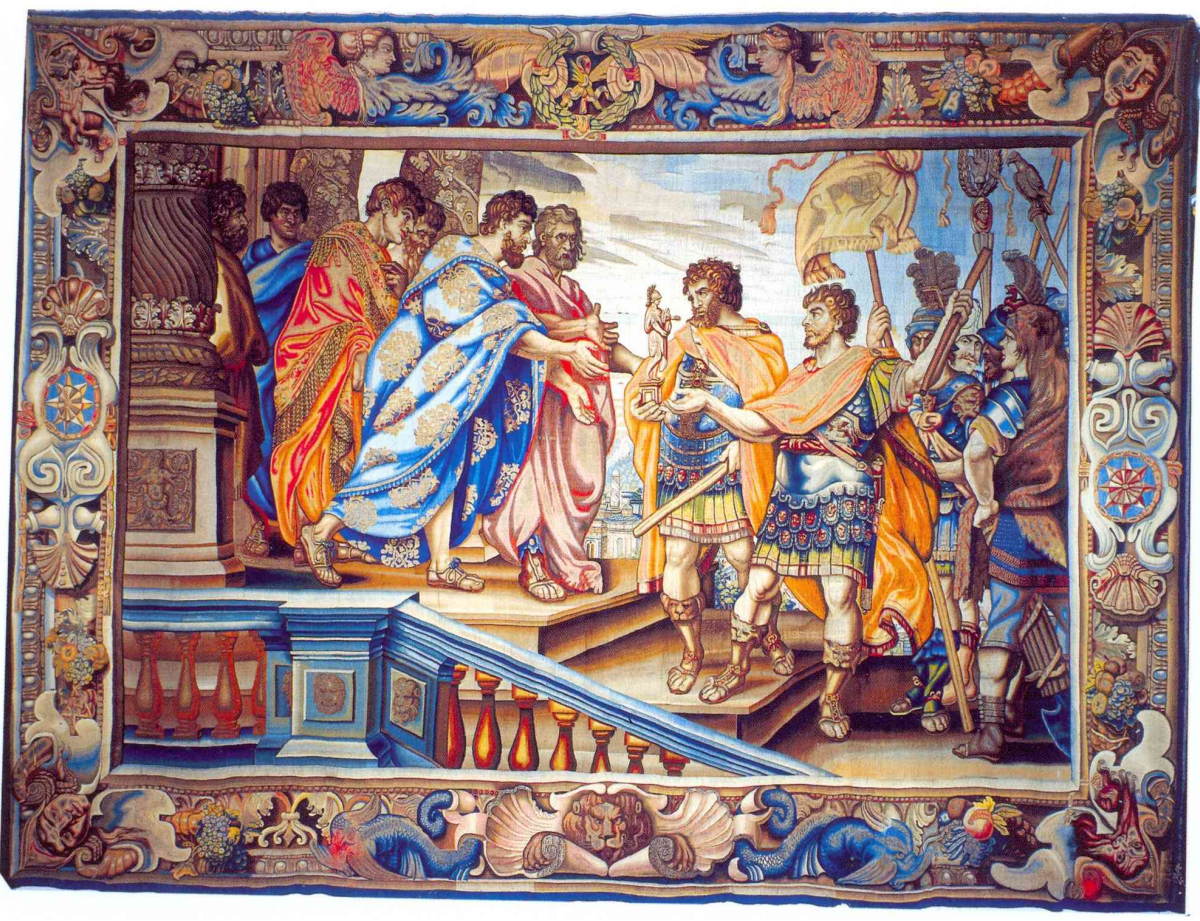

Figura 7. 


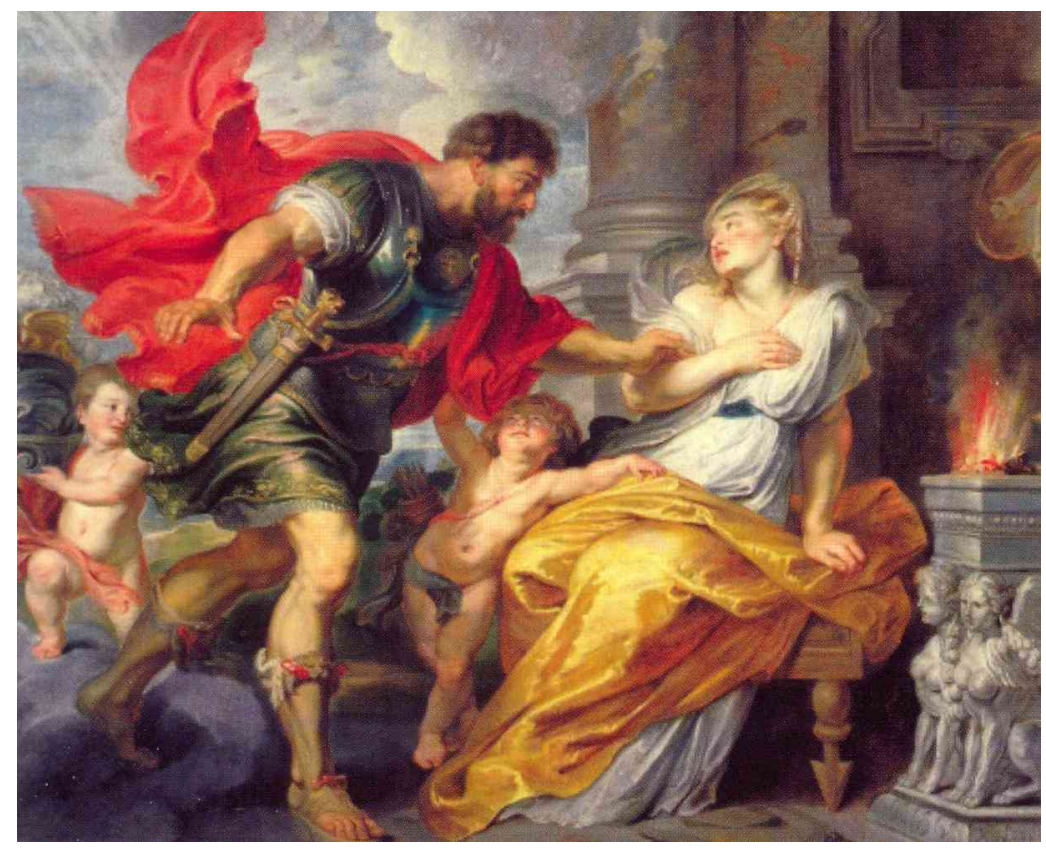

Figura 8.

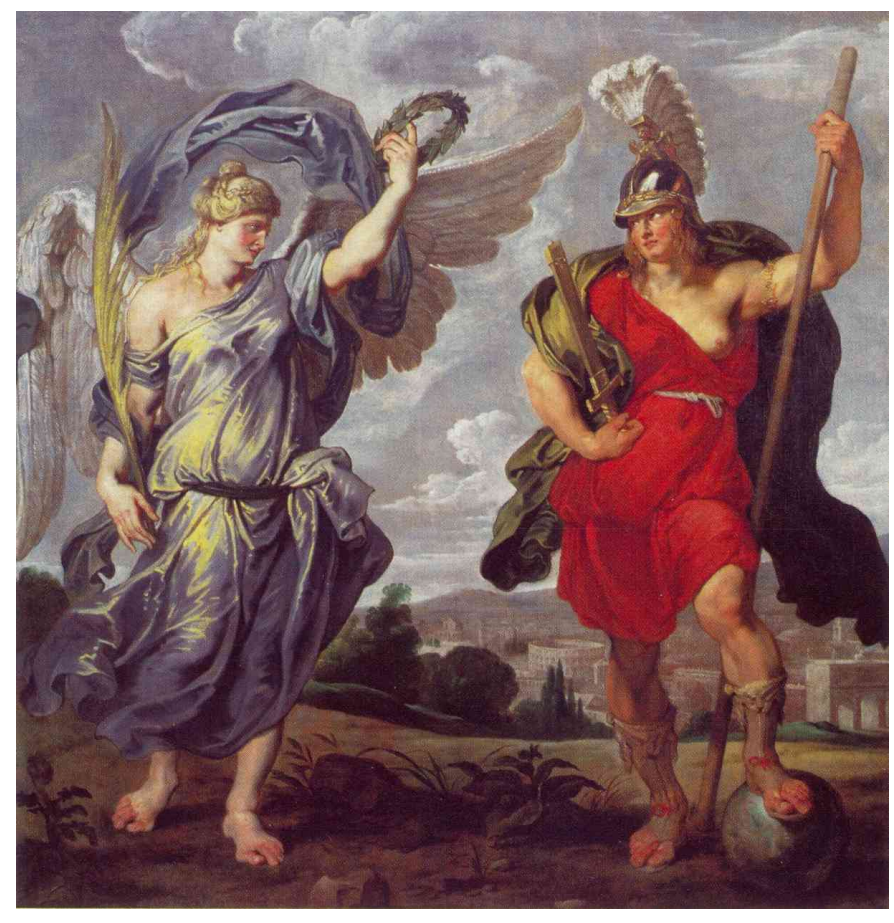

Figura 9. 